\title{
Antracnose em Paphiopedilum insigne (Orquidaceae) Causada por Colletotrichum gloeosporioides
}

\author{
Reginaldo G. Mafia, Acelino C. Alfenas, Gizella M. Ventura \& Rafael F. Alfenas \\ Departamento de Fitopatologia, Universidade Federal de Viçosa, UFV, CEP 36570-000, Viçosa, MG, e-mail: aalfenas@ufv.br
}

(Aceito para publicação em 12/01/2005)

Autor para correspondência: Acelino Couto Alfenas

\begin{abstract}
Anthracnose in Paphiopedilum insigne (Orquidaceae) caused by Colletotrichum gloeosporioides

Anthracnose caused by Colletotrichum gloeosporioides is reported for the first time in Paphiopedilum insigne

(Orquidaceae) in Brazil. The disease was observed in Entre Rios de Minas, Minas Gerais, Brazil.
\end{abstract}

No Brasil, as orquídeas constituem um dos principais grupos de plantas ornamentais explorados comercialmente (Castro, C.E.F. Revista Brasileira de Horticultura Ornamental 4:1-46. 1998). Em relação às doenças, a antracnose causada por Colletotrichum gloeosporiodes (Penz.) Penz. \& Sac. destaca-se como uma das mais importantes, sobretudo sob condições de elevada umidade. Em inspeção de rotina em um orquidário em Entre Rios de Minas (MG), observou-se a incidência de manchas foliares de coloração marrom a marrom escura contendo conidiomas acervulares em plantas de Paphiopedilum insigne (Wall. ex. Lindl.) Pfitzer (Figura 1A), cuja espécie é conhecida popularmente como sapatinhode-vênus.

A doença caracteriza-se pela presença de manchas foliares (Figura 1B) circulares, bem delimitadas e deprimidas (Figura 1C), inicialmente escuras e circundadas por halo de coloração marrom (Figura 1D, a). Com o progresso da lesão, o centro assume cor marrom clara ou esbranquiçada e o halo apresenta-se escuro (Figura 1D, b). A colonização do tecido foliar é intensa e sobre a lesão, sobretudo em períodos de maior umidade, observam-se massas de esporos de coloração creme, produzidas em conidiomas acervulares (Figura 1E), que contêm conidióforos, conídios (Figura 1F) e setas típicas do patógeno C. gloeosporioides. Os conídios do fungo são hialinos, elípticos e de dimensões médias iguais a 17 x 4,5 $\mu \mathrm{m}$, enquanto as setas são de coloração marrom escuro e de extremidade marrom clara. Com base em relatos da doença em outras espécies orquidáceas, sabe-se que este fungo pode afetar qualquer parte da planta, principalmente quando existem lesões produzidas pela incidência de raios solares diretos, por ação mecânica, entre outras causas. A comprovação da etiologia foi realizada depois de confirmar a presença de $C$. gloeosporioides em lesões obtidas a partir da inoculação de folhas com o mesmo fungo isolado de amostras de plantas doentes, cujas infecções ocorreram naturalmente. A inoculação consistiu na deposição de massa de esporos sobre ferimentos, realizados em folhas destacadas com auxílio de um conjunto de agulhas, e incubação em câmara úmida a $28 \pm 2{ }^{\circ} \mathrm{C}$ e luminosidade de $36 \mu \mathrm{mol} \cdot \mathrm{m}^{-2} \cdot \mathrm{s}^{-1}$. Após cinco dias de incubação, contatou-se a presença de sintomas e sinais típicos da doença, observados sob condições de infecção natural.

O controle da doença pode ser alcançado pela remoção e destruição das folhas doentes e evitando-se o molhamento das folhas para reduzir o microclima favorável à infecção e assim minimizar a produção de inóculo.

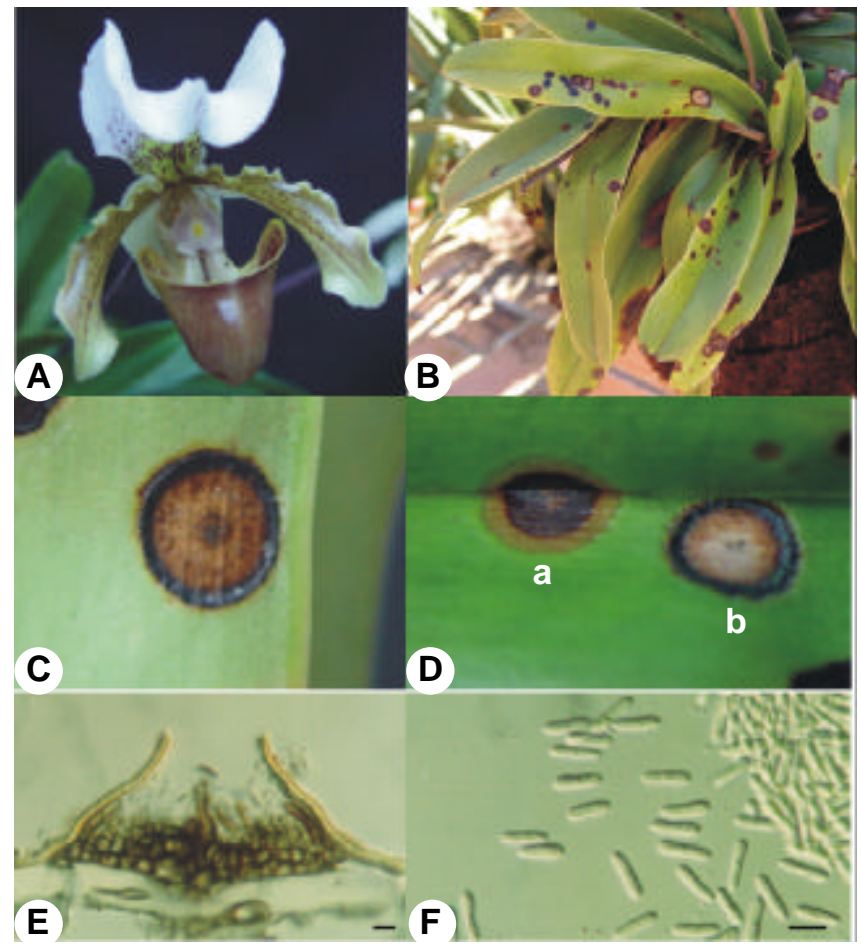

FIG. 1 - Sintomas e sinais de antracnose causada por Colletotrichum gloeosporioides em Paphiopedilum insigne: A- Flor típica da espécie; B- Sintomas de manchas foliares: C- lesões circulares, bem delimitadas e deprimidas; D- Progresso da lesão evidenciando manchas inicialmente escuras, circundadas por halo de coloração marrom (a) que posteriormente se tornam de centro marrom claro ou branco e com halos escuro (b); E- Conidioma acervular; e FConídios típicos de C. gloeosporioides. Barras $=20 \mu \mathrm{m}$. 